\title{
Evaluating the strategic plans of public libraries: an inspection-based approach
}

\begin{abstract}
For public libraries, as with most organisations, effective strategic planning is critical to longevity, facilitating cohesive and coordinated responses to ever present and ever changing political, economic, social, and technological (PEST) forces which shape and influence direction. However, strategic planning is widely recognised as a challenging activity, which can be both time consuming and unproductive, and there exists limited guidance regarding how to evaluate documented and disseminated strategic plans, particularly within the not-for-profit sector. In response, this research proposes and tests an inspectionbased approach to the evaluation of strategic plans, based upon a rubric specifying the key attributes of each of the core components of a plan, combined with an appropriate assessment scale. The rubric provides a method to identify and assess completeness of strategic plan, extending to qualitative assessment of communication aspects such as specification and terminology, and synergistic aspects such as cohesion and integration. The method is successfully trialled across the devolved Scottish public library sector with the strategic plans of 28 of the 32 regional networks evaluated. 17 of 28 plans $(61 \%)$ were found to be incomplete and/or to contain contradictory or uncoordinated components, with it recommended that Scottish public libraries improve not only completeness of plans, but also their precision, specificity, explicitness, coordination, and consistency, and overall mapping to library services. Recommendations are made for further widespread application of the rubric.
\end{abstract}

\section{Introduction}

In an era of unprecedented technological innovation, evolving user expectations and information seeking behaviour (Leong, 2008; Parry, 2008), and challenging economic times, strategic planning is arguably now more than ever of critical importance to the public library sector, for required responses are multifaceted and multiparty. However, strategic planning is widely recognised as a challenging activity (Koch, 2000), which within the library sector, can be both time consuming and unproductive (Linn, 2008). Yet strategy is key to longevity, providing overarching direction, and facilitating cohesive and coordinated responses to increasingly dynamic political, economic, social, and technological (PEST) forces which shape and influence direction.

Beginning with identification of the core components of a strategic plan and specification of associated quality attributes, this research proposes and applies an inspection-based approach to the evaluation of documented strategic plans, based upon a novel assessment rubric. The method is applied across the devolved ${ }^{1}$ Scottish public library sector, encompassing 28 of the 32 public library regional networks, serving a wide-ranging urban and rural demographic. Findings are discussed, including emergent strategic themes, and recommendations made. To the best of our knowledge, this is the most comprehensive study of its kind to date, contributing to our understanding of evaluative techniques applicable to strategic plans, and providing indicative findings regarding quality of strategic plans across an entire public library sector.

\section{Problem statement}

Although strategic planning is a recognised discipline within library management, there is evidence suggesting that acceptance is limited (Rowley et al., 1997; McClamroch et al., 2001; Linn, 2008). Llewellyn and Tappin (2003) argue that this may be partly due to its association with the private sector and competitive advantage, as opposed to public sector social value; however, notwithstanding that strategic planning should not be defined in revenue or social terms, but recognised as a means of guiding a library through a period of time, there is a danger that if strategic plans do not arise from within, libraries

\footnotetext{
${ }^{1}$ In accordance with the Scotland Act 1998, Scottish public libraries are the devolved (within the UK) responsibility of the Scottish Government, guided by the Scottish Library and Information Council (SLIC), an independent advisory body.
} 
will be directed by outside forces with independent motivations and inadequate understanding of their broader societal role (Johnson et al, 2004; Kent, 2002).

This particular study arose from ongoing parallel research investigating emergent digital services in the Scottish public library sector, such services arguably being of critical (and strategic) importance to public library longevity in the digital era. Preliminary findings of this research identified significant inconsistency of digital services offered, and associated problems of disparity and duplication (Buchanan \& McMenemy, 2010); and raised a valid research question regarding the degree, and quality, of associated strategic planning. Recognizing that existing evaluative approaches, typically focused on strategic planning processes and/or measurement of outcomes (Drumaux and Goethals, 2007) are potentially complex and resource intensive (Rossi et al, 2004; Linn, 2008), and hypothesising that documented and disseminated strategic plans are an important subject of evaluation in their own right (a hypothesis supported by a recent study within the private sector by Hahn $(2010$, p.76) which found "a statistically significant performance advantage associated with strategic plan quality and implementation capability"); focused our attention on the evaluation of associated strategic plans, which we reasoned would be more straightforward and less resource intensive than an investigation of planning processes, but equally insightful (and facilitating a 'national' perspective). However, this raised a further research question regarding appropriate approach, and highlighted a particular research problem, a lack of existing guidance regarding how to evaluate strategic plans, particularly within the non-profit sector (Chance \& Williams, 2009; De Carlo et al., 2008, Allison \& Kaye, 2005). We subsequently arrived at two research goals: to investigate public library strategy, and to contribute to understanding of appropriate evaluative techniques.

\section{Literature review}

Smith (1994, p.7) describes strategic planning as "an opportunity to analyse carefully the purpose of the organization, and to consider what strategies can actually deliver that purpose". Bryson (2004, p.7) notes that "strategic planning is not a single thing, but a set of concepts, procedures and tools", reminding us that strategic planning is a formal approach to defining and planning which more broadly, aims to understand the environment in which the library operates, which is then commonly expressed and disseminated as a documented strategic plan. Importantly, strategic planning should not be confused with strategic management as the former is concerned with setting direction, the latter with operational governance.

Various strategic planning frameworks and processes have been proposed over time, but Buchanan (2010) argues that although terminology differs across authors, there is underlying commonality of purpose. Buchanan illustrates this point by comparing public and private sector frameworks (Chaffey, 2002 writing for e-business; Roberts and Rowley, 2004 writing for information services; Allison and Kaye, 2005 writing for non-profit organisations), mapping commonality, and distilling the planning process down to four common steps: internal/external organisational 'analysis'; 'formulation' of plans; 'implementation' of plans; and 'evaluation' of outcomes. For the purposes of our study, our first step was not to re-examine planning processes, but to arrive at a generic specification for a strategic plan that would guide subsequent evaluations. We therefore sought to identify the core components of a strategic plan, and in particular, qualitative attributes of each respective component.

\subsection{Core components of the strategic plan}

Often when strategy is discussed, reference is variously made to mission, vision, goals, objectives, and action plans. It is important to note that these are not synonymous terms, but discrete components of an articulated strategic plan. Perhaps not surprisingly, given that there is no standard definition for a strategic plan, terminology, content, and structure differs across authors (for example see indicative table of content specifications provided by: Allison and Kaye, 2005, p. 252; Pacios, 2007, p. 417; Bryson, 2004, p.208; Harriman, 2008, p.13); however, there is general broad agreement on the core components of a plan, as discussed below.

\subsubsection{Mission Statement}


Corrall (2000, p.78) describes a mission statement as: "a concise summary in a few sentences or paragraphs of the organisation's purpose or reason for existence." Bryson (2004, pp. 114-117), writing for the public sector, identifies six questions fundamental to development of a mission statement: who are we; what are the basic social and political needs we exist to meet, or what are the basic social and political problems we exist to address; what do we do to recognize, anticipate, and respond to these needs or problems; how should we respond to our key stakeholders; what are our philosophy, values, and culture; what makes us distinctive or unique? Similar to Corrall, Bryson (2004) recommends that mission statements be succinct, targeted, activist in tone, and inspiring.

\subsubsection{Vision Statement}

The vision statement is an opportunity for an organisation to state to what it aspires, best articulated in a challenging and future oriented manner (Siess, 2002). It is often viewed as an abstract statement as it does not incorporate an explicit evaluative function due to its visionary nature (Kirkpatrick 2008; Hartzell, 2002). However, although a vision statement may not describe specifics - banal, generic statements that commit to nothing should be avoided as they lack meaning or value (Baker, 2004; Corrall, 2000). In contrast, a specific, inspiring and challenging vision statement facilitates motivating and meaningful ambition (Brockmann \& Clifford, 2008).

\subsubsection{Goals}

Corrall (2000, p.103) describes goals as "the medium-term objectives that represent the developments, initiatives or improvements required to move the organisation forward". Goals are developed from the mission and vision statements and should be measurable and time-bound (Siess, 2002). Goals should also be achievement oriented, specific, realistic, stated as ends, and suited to translation into targets (Corrall, 2000; Smith, 1994). Associated targets should be well defined, measurable, realistic in timetable, and incorporate checkpoints (Harriman, 2008).

\subsubsection{Objectives}

Objectives are specific, quantifiable and attainable short-term targets, which are used to measure the degree to which the organisation is realising goals. Objectives should be time-limited, and associated with unambiguous and measurable criteria for success. Objectives are often hierarchical (Baker, 2004; Corrall, 2000) and should also be measurable, verifiable, and actionable (Riggs, 1984; Flamholtz and Kurland, 2006).

\subsubsection{Action Plans}

Action plans define the specific steps to be taken to realise goals and objectives, typically realised as a project plan. Action plans can be strategic (long-term) or tactical (short-term), but are typically short-term covering one year or less (Bryson, 2004). Action plans specify the resources necessary to achieve goals and objectives, defining responsibility, budget, and timelines (Harriman, 2008). They should be explicitly traceable (linked) to longer-term goals and objectives. Action plans can be optional within the strategic plan itself, but in such cases explicit reference should be made to their existence elsewhere (with the strategic plan regarded as the master plan).

The above components and key associated attributes are summarised in Table 1.

As well as the core components illustrated in Table 1, a documented strategic plan should also, as a minimum, include a title (including subject and time span), an executive summary, introduction, and supporting background information were necessary (Corral, 2000).

It is important to note that Allison \& Kaye (2005) argue that the format, specificity, and length of a strategic plan will vary dependent upon the intensity of the planning process, and in relation, suggest that 
the documented output of an 'abbreviated' planning process might not include goals and objectives. While we concur with the former point we have reservations concerning the latter, considering goals and objectives integral components of a plan critical to implementation. An abbreviated approach might be valid in certain circumstances but there is a lack of clarity from the authors concerning exactly what those circumstances might be (and the authors themselves later refer to goals and objectives as 'at the heart of a strategic plan' (p.254)). We consider the components in Table 1 as core to a strategic plan, with only action plans optional.

Table 1. The components and key attributes of a strategic plan

\begin{tabular}{|l|l|}
\hline Component: & Should be: \\
\hline \multirow{4}{*}{ Vision } & Specific \\
\cline { 2 - 2 } & Inspiring \\
\cline { 2 - 2 } & Challenging \\
\hline \multirow{4}{*}{ Mission } & Purposeful \\
\cline { 2 - 2 } & Targeted \\
\cline { 2 - 2 } & Stakeholder focused \\
\hline \multirow{4}{*}{ Objeals } & Stated as ends \\
\cline { 2 - 2 } & Specific \\
\cline { 2 - 2 } & Translatable \\
\cline { 2 - 2 } & Traceable \\
\hline \multirow{4}{*}{ Action Plans } & Specific \\
\cline { 2 - 2 } & Measurable \\
\cline { 2 - 2 } & Time-bound \\
\cline { 2 - 2 } & Measurable \\
\cline { 2 - 2 } & Time-bound \\
\cline { 2 - 2 } & Linked \\
\cline { 2 - 2 } & Resourced \\
\hline
\end{tabular}

\section{Methodological approach to evaluation}

As previously noted, although much has been much written on strategic planning, there is limited guidance as to how to evaluate fitness-for-purpose and quality of associated strategic plans, particularly for the non-profit sector (Chance \& Williams, 2009; De Carlo et al., 2008, Allison \& Kaye, 2005). Evidence suggests that when strategic planning is evaluated, the research method is often based on interviews with planners regarding the strategic planning process, or measurement of outcomes (Drumaux and Goethals, 2007; De Carlo et al., 2008). As a consequence, studies evaluating strategic plans are limited.

McNicol (2005), investigating strategic planning in UK academic libraries adopted a multi-method approach (document analysis, interviews, and survey). McNicol discusses reviewing a sample of strategic planning documents from 12 institutions, but does not specify how the review was conducted or specific criteria adopted. Findings related specifically to plans are limited to general observations, with more in-depth findings related to the planning process and institutional (University) alignment.

Kettunen (2007) applied a balanced scorecard approach to the evaluation of strategic plans within a consortium of digital libraries across 29 Finnish universities, but at a high level based on four perspectives (customer, finance, internal processes, and learning), and focused on implementation. Methodology is only provided in overview, and evaluation limited to general observations.

Pacios (2007) conducted comparative analysis of the strategic plans of 73 US public libraries to investigate trends in library priorities. However, the description of the methodology is limited, and although mention is made of missing components or sections within plans, and "ambiguous or not sufficiently specific language" (Pacios, p.417), the study itself focused on the identification and categorisation of emergent trends and themes, rather than the plans themselves.

Usefully for the purposes of our study, Chance and Williams (2009, p.45), investigating strategic planning within higher education, and describing strategic planning as a "complex design assignment", developed 
a rubric to evaluate strategic plans based upon strategic components mapped to four levels of quality indicators (excellent, good, fair, inconsequential), structured according to Holcomb's (2001) five planning questions: where are we now; where do we want to go; how will we get there; how will we know we are getting there; and how will we sustain focus and momentum? A rubric was considered appropriate as it provided "a way to achieve a comprehensive, holistic assessment", and "graphically illustrate relationships between performance criteria" (Chance \& Williams, p.45). Chance and Williams applied the rubric to two University strategic plans, arriving at scores for each component and an overall evaluation score for each plan (describing the latter as a "holistic" evaluation arrived at separately from the former, i.e. not solely calculated from individual component scores). Unfortunately Chance and Williams do not provide the numerical scale nor actual scores arrived at (neither is it entirely clear how overall 'holistic' scores are arrived at), but the rubric nonetheless provides a novel framework to guide assessment of strategic plans, and to explore further.

Chance and Williams (2009) concluded that, with further field-testing, the rubric holds promise for widespread use, but cautioned against automatic use of the component descriptors contained within, considering these to be potentially variable on an organisation by organisation basis. We concurred, utilising the rubric as the basis of our own approach, but with two refinements. Firstly, while Chance and Williams listed and assessed all components of a plan from the introduction to the appendices (based on a table of contents for a strategic plan provided by Allison \& Kaye (2005)) we elected to focus on the core components of a plan (as defined in Section 2.1), considering 'introduction', 'executive summary', and 'appendices' etc. important to the document, but ancillary to assessment of the actual plan (and potentially duplicative). Secondly, with respect to the quality levels, we added an explicit numerical scale, changed the 'fair' category to 'poor' (considered more appropriate given the description), and changed the 'inconsequential' category to 'absent' (considered more objective and appropriate). The arrived at evaluation scale is illustrated in Table 2, which when combined with Table 1 (providing specific attributes for respective components), provided our adapted rubric.

Table 2. Evaluation scale (derived from Chance and Williams (2009))

\begin{tabular}{|c|c|l|}
\hline Excellent & 3 & Clearly and thoroughly addressed and well coordinated with other components. \\
\hline Good & 2 & Largely addressed but incomplete and/or uncoordinated. \\
\hline Poor & 1 & Largely unaddressed. \\
\hline Absent & 0 & Not addressed. \\
\hline
\end{tabular}

Through identification of components and subsequent evaluation of specific associated attributes a score could then be arrived at regarding the degree to which each individual component is addressed within each plan, which when totalled, would provide a total score indicating completeness and quality of plan. Utilising the scale in Table 2, a total score of 15 is possible if all components of a strategic plan are present and all associated key attributes are met, suggesting an overall rating of 'excellent', and raising a question regarding appropriate assignment of values to scores between $0-14$. For example, via implicit intervals suggested by the scale (multiplied by number of components assessed), it would be possible to associate an overall score between 0-4 with 'absent', between 5-9 with 'poor', between 10-14 with 'good', and 15 with 'excellent', but are these appropriate, particularly for scores +/- 1 of upper/lower limits? An alternative approach would be to set intervals by midpoints, with scores between 0-3 considered 'absent', 4-8 'poor', 9-13 'good', and 14-15 'excellent', which while remaining problematic, does marginally adjust intervals, particularly at upper/lower ends. Limitations acknowledged we elected to proceed with the latter, with the intervals considered slightly better dispersed. It is important to note that deliberations were guided by pragmatic recognition that we are applying a numerical scale to an essentially qualitative assessment, and that as a consequence, findings would be indicative rather than absolute as scores would be to a degree, subject to interpretation (a problem inherent within rubrics of this nature - for example, consider assessment rubrics within education, from which this approach is derived). A 
definitive, objective score would only be possible where simply evaluating the existence (or not) of individual components, but this would be at the expense of quality considerations.

In parallel, inherent content analysis facilitated holistic observation regarding communication aspects such as specification and terminology, and synergistic aspects such as cohesion and integration (of components). It should be noted however that assessment did not extend to judgements regarding appropriateness of individual strategy, as this was considered situational and out with the scope of this investigation (being more appropriate to in-depth investigations of decisions made during planning processes). However, emergent strategic themes are reported, facilitating general observations.

Strategic plans were obtained via Freedom of Information (FOI) request, with each of the 32 local authorities in Scotland asked to provide the strategic plan or equivalent document for public library services within their respective authority. The FOI (UK) act 2000 and FOI (Scotland) act 2002 provide the public with a general right of access to information held by public authorities. The FOI act is intended to encourage open government and public participation, and to enhance democracy and accountability (Chapman \& Hunt, 2010). Beyond benefit of return, FOI request ensured that we reviewed endorsed documents supplied by respective authorities, rather than public documents obtained by other means. Plans were collated September to December 2009. In consideration of the sensitive nature of this study and possible political and organizational ramifications of findings presented, anonymity of individual libraries is respected.

\section{Findings}

Within the UK, Scottish public libraries are the devolved responsibility of the Scottish Government, represented in the Scottish Parliament by the Scottish Library and Information Council (SLIC), acting as an independent advisory body. In total, there are 32 regional library networks corresponding to the 32 local authorities of Scotland, serving a wide-ranging urban and rural demographic, stretching from the southern Scottish Borders through the central belt encompassing Glasgow and Edinburgh, to the remote northern isles of Orkney and Shetland. Each library network is governed and administered by its respective parent local authority, which provides overarching direction and distributes budgets (across various local public services).

In total, 28 of 32 local authorities responded to FOI request, with 8 (29\% (rounded)) returning multiple documents (from 2 to 10), variously ranging from 1-117 pages in length. 18 of 28 (64\%) provided dedicated library plans, while $10(36 \%)$ provided parent local authority plans incorporating library plans. In the latter instance, only those components of the plan that made direct reference to library services were considered within the scope of this study. 10 of 28 plans (36\%) covered a one-year period, and with the exception of one, were variously referred to as 'service plans', 'resource plans', or 'service improvement plans', rather than strategic plans. This was the first notable observation, as such plans can arguably be considered operational rather than strategic (with the exception being short-term tactical strategic plans, which none were identified as). Of further concern was that 4 of 28 plans (14\%) specified no time period. The remainder ( 14 of 28 , or $50 \%$ ) were $3-4$ year plans variously covering the period $2008 / 9-2011 / 12$, with the exception of one, covering the period 2009-2014.

16 of 28 plans $(57 \%)$ included vision statements, but in several instances the statement was more activity based and informative than inspirational. In several plans, distinction between vision and mission was blurred, but more importantly, several statements were parent local authority statements not specific to library services. The median component score (out of 3 ) for vision statements was 1.5 .

20 of 28 plans $(71 \%)$ included mission statements; however, in several instances the mission was not presented as a discrete statement but was implicit within service statements (what is provided, for whom, and why). Identifiable service themes included: early learning, scholarship, genealogy and heritage, enterprise and employment, reading, and reference enquiries etc. If mission was recognisable in a clear and concise way within such service statements, the plan was deemed to implicitly include a mission statement (which could be considered generous). The median component score (out of 3) for mission statements was 2.0 . 
All 28 plans variously included discernible goals, but not always expressed at a consistent level of detail with some more akin to short-term objectives, or describing specific tasks more commonly associated with lower level plans of action (Presley and Leslie (1999) argue that such inconsistency can encourage divergence and reduce coherence during implementation). In those instances were the library plan was inherent within the parent local authority plan, there were instances were local authority goals applicable to public libraries, such as those associated with lifelong learning, did not explicitly reference the associated role of the library service. The median component score (out of 3 ) for goals was 2.0.

20 of 28 plans $(71 \%)$ included objectives; however, in the majority of instances they were considered too broad to be specific, measurable, and time-bound. It was noted that in several local authority strategic plans, objectives were the first point at which libraries were explicitly referred to (i.e. higher level goals, mission and vision statements did not make explicit reference to library services) raising questions regarding strategic role and contribution (within the local authority). The median component score (out of 3) for objectives was 1.0 .

20 of 28 plans (71\%) included some kind of action plan. Action plans were sometimes associated with entire goals, and sometimes objectives within goals. As previously noted (see Section 3.5), action plans are optional in strategic plans, but in those instances, explicit reference should be made to their existence elsewhere. This was not evident. The median component score (out of 3) for action plans was 2.0.

With regard to general observations regarding communication aspects such as specification and terminology, and synergistic aspects such as cohesion and integration, plans suffered from a number of similar problems. Consistency, precision, explicitness and specificity were issues to varying degrees in the majority of plans, and terminology was inconsistent in several instances. Several of the plans comprised multiple documents, but in several instances relationships were only stated in the FOI response, not in the documents themselves, with master documents not always self-apparent, or links between clearly mapped. 9 of 28 plans (32\%) lacked explicit upstream/downstream linkage between library specific strategy and parent local authority strategy. A high-level parent plan may make limited reference to the library service, but there is nothing to stop the library plan (or equivalent statements) making repeated reference to the parent plan.

8 of 28 plans (29\%) contained no action plans (and made no reference to their existence elsewhere). 4 of the 8 contained no objectives either. A particular issue with such documents, possibly written for public consumption rather than practical use, is that it can be difficult to use such documents to guide internal decision-making (without stating the 'why' that motivates the 'who', 'what', 'when', 'where' and 'how' (Stuart and Moran, 1998)). There is a valid argument that high-level parent local authority plans, encompassing multiple divisions and services, cannot accommodate specific and detailed implementation plans, but of the 8 plans without objectives and/or action plans, 5 were library specific plans.

Several plans made reference to the Public Library Quality Improvement Matrix (PLQIM) and some incorrectly used this as the basis for their strategic plan. The Scottish Library and Information Council (SLIC) and the Scottish Executive developed the PLQIM to provide a matrix for assessing the quality and range of services delivered (Scottish Executive and SLIC, 2007). The PLQIM is a quality assurance tool and while it recommends that library services be delivered within a strategic framework, the seven quality indicators were not intended as such a framework.

With regard to actual strategic intent expressed within plans, four common overarching themes emerged:

- Community planning and partnership working: reaching out not only to users but also to potential partners within the community who are in a position to enhance services offered.

- Social inclusion: ensuring that library services are open to all, and striving to reach those excluded for health, financial, geographic, or intellectual reasons (bridging inequality).

- Promotion of reading and literacy: promoting reading and literacy across the community, targeting inequality, and creating a smarter citizen.

- Accessibility of services: ensuring that services are accessible to as many users as possible. 
An emphasis on services that reach out to users was evident, and reflected in discourse, with terms such as "empowering" and "promoting" used frequently, suggesting a desire to be more proactively involved in local communities. Digitization goals were also evident (and often highlighted as a priority or key direction), but with few exceptions, associated objectives were noticeably absent or broadly and generically defined, with limited supporting specification. This may go some way to explaining why previous research (Buchanan \& McMenemy, 2010) investigating emergent digital services in this sector, reported widespread inconsistency, disparity, and duplication.

With respect to total scores (out of 15), 1 of 28 strategic plans (4\%) scored within the 0-3 interval range (corresponding to absent), 16 of $28(57 \%)$ within the 4-8 interval range (corresponding to poor), and 11 of $28(39 \%)$ within the 9-13 interval range (corresponding to good). No strategic plan scored within the 1415 interval range (corresponding to excellent). The lowest total score was 3 , the highest 12 . The median total score (out of 15 ) was 7.5 . From these findings, $61 \%$ of plans were rated as poor or below.

For Scottish public libraries, a number of clear recommendations arise:

- Within parent local authority plans, public libraries should be explicitly referenced and represented at the goal level as a minimum, with mission and vision clearly applicable to library services. Anything less limits their strategic contribution.

- Completeness of individual plans should be addressed with particular attention to precision, specificity, and explicitness, and overall coordination and consistency with partner and parent organisations.

- A guide for strategic planning, similar to the PLQIM for quality assurance, is recommended, and in particular, to draw attention to the importance of setting and articulating challenging and inspiring strategic direction in vision/mission statements, and translating goals into action via objectives and action plans. The authors envision the guide as a framework supported by practitioner group, providing step-by-step methodological guidance incorporating and/or referencing appropriate tailored tools, templates, and checklists. Building upon existing guides for the public and non-profit sector (e.g. Allison \& Kaye, 2005; Bryson, 2004), this would be practitioner developed and importantly, incorporate development of a shared resource base (populated with exemplar library plans and case studies etc.) to encourage knowledge exchange and collaboration. Such a group might be formed via professional and/or statutory body.

\section{Discussion}

That 28 of the 32 regional library networks consider themselves to have strategic plans is encouraging, but from the findings of this study, which rate $61 \%$ as incomplete, and containing contradictory or uncoordinated components; it is clear that further planning effort is required. It should be reiterated that planning is widely acknowledged as a challenging activity, and noted that findings may not be untypical, even when compared to the private sector with which the activity is more commonly (if incorrectly) associated. For example, while we lack a directly comparable study, Koch (2000, p.241) has previously estimated that only $10 \%$ of large UK private firms, $20 \%$ of large US firms, and $50 \%$ of large Japanese firms have a clear sense of mission.

Reflecting on our methodological approach, we believe that the rubric provides a method to identify and assess completeness of strategic plans, and facilitates qualitative assessment of associated communication aspects such as specification and articulation, and synergistic aspects such as overall cohesion and integration, as evidenced by our findings. We found the rubric relatively intuitive to understand and apply, and in contrast to alternative approaches that evaluate the strategic planning process and/or measure outcomes, arguably does not require expert strategic planning knowledge or measurement skills. As previously highlighted, there is a degree of subjectivity to the assessment method, but we believe this is partially mitigated by clear and specific evaluation criteria for each strategic component. We have applied the method across a sector (demonstrating potential as a benchmark tool), but the method can be equally applied on an individual basis, and given perceived usability, will hopefully 
encourage self-evaluation within public libraries (and more widely given the rubric is not library specific). We unreservedly encourage further trials and refinement of this method.

Providing a relatively simple and straightforward approach that facilitates self-evaluation within libraries is both important and timely, as evidenced by a recent study by Piorun (2011), published at time of our own write-up. Piorun (p.54), arguing that "a deeper understanding of how strategic plans are evaluated is the first step in assessing the value of strategic planning for libraries", investigated evaluation methods applied within 5 US academic medical libraries during strategic planning, and found that approaches varied widely, with 4 of 5 reliant on informal means of questionable reliability. Through interview and focus group Piorun identified a number of barriers to evaluation, not least that librarians "believed that they did not have the time and training necessary to learn how to apply, develop, and implement complex evaluation studies" (p.60), and that as a consequence, they found evaluation to be "overwhelming" (p.60). Yet evaluation is widely acknowledged as critical to the planning cycle and as evidenced here, to assessing quality of associated plans.

\section{Limitations}

FOl undoubtedly encouraged return, but it is possible to argue that this research was limited by a general FOI request that returned multiple levels of document not necessarily directly returned by library representative and therefore not necessarily best placed to provide this information. A further limitation was a nascent rubric, and the associated inherent limitations of undertaking qualitative evaluation open to subjective interpretation (mitigated to a degree by team review of findings, but perhaps benefiting from a larger team). Further research will advance and further test the rubric, while second independent assessment of our sample would verify findings.

\section{Conclusion}

This research tested an inspection-based method to evaluate strategic plans based upon a rubric that specifies the key attributes of each of the core components of a strategic plan and provides an associated evaluation scale. Successful trial across the devolved Scottish public library sector demonstrated that the method can be used to identify completeness of strategic plans, and that it also facilitates qualitative assessment of associated communication aspects such as specification and articulation, and synergistic aspects such as overall cohesion and integration. A further benefit to this approach is that the rubric is relatively intuitive to understand and apply, and in contrast to alternative approaches that evaluate the strategic planning process and/or measure achievement of outcomes, arguably does not require expert knowledge or major resource investment, encouraging broad application. A major benefit of an inspection-based approach is that it offers immediacy, highlighting issues within the plan that might influence likelihood of successful outcome (as opposed to evaluating long term success or failure 1-3 years post plan).

That 28 of the 32 Scottish regional library networks consider themselves to have strategic plans is encouraging, but from the evidence presented, which rated $61 \%$ as incomplete, and containing contradictory or uncoordinated components; it is clear that there is a need for guidance on the components to be included in a strategic plan and how to ensure fitness-for-purpose. Further, in a number of instances, there is also an issue regarding explicit representation at the strategic level within parent organisations, particularly were no separate strategy document exists specific to the library service. This significant issue is not exclusive to public libraries or to Scotland, as McNicol (2005) reports similar findings in a study of UK academic libraries. Given these findings, of particular concern is how libraries are effectively responding to, and influencing change, in these uncertain times.

\section{References}

Allison, M., \& Kaye, J. (2005). Strategic planning for nonprofit organizations ( $2^{\text {nd }}$ ed.). New York: John Wiley. Baker, D. (2004). The strategic management of technology. Oxford: Chandos. 
Brockmann, E.N. \& Clifford, M.K.Jr. (2008). Strategic planning: a guide for supervisors. Supervision, 69(8), 3-9.

Bryson, J.M. (2004). Strategic planning for public and non-profit organizations: a guide to strengthening and sustaining organizational achievement ( $3^{\text {rd }}$ ed.). San Francisco, CA: Jossey-Bass.

Buchanan, S. (2010). Planning strategically, designing architecturally: a framework for digital library services. In A. Woodsworth (Ed.), Advances in librarianship: exploring the digital frontier, 32, pp. 159180. Bingley, UK: Emerald Group Publishing Ltd.

Buchanan, S., \& McMenemy, D. (2010). Towards a public library digital service taxonomy. In M. Lalmas, J. Jose, A. Rauber, F. Sebastiani, \& I. Frommholz (Eds.), Lecture Notes in Computer Science 6273: Research and Advanced Technology for Digital Libraries, $14^{\text {th }}$ European Conference, ECDL 2010, Glasgow, UK, September 2010 Proceedings, pp. 425-428. Berlin: Springer.

Chaffey, D. (2002). E-business and E-commerce management. Harlow: Financial Times Prentice Hall. Chapman, R.A., \& Hunt., M. (Eds.) (2010) Freedom of information: local government and accountability. Surrey: Ashgate Publishing Ltd.

Chance, S. \& Williams, B.T. (2009). Assessing university strategic plans; a tool for consideration. Educational Planning,18(1), 38-54.

Corrall, S. (2000). Strategic management of information services: a planning handbook. London: Aslib/IMI.

De Carlo, M., Cugini, A. \& Zerbini, F. (2008). Assessment of destination performance: a strategy map approach. Tourism Review, 63(2), 25-37.

Drumaux, A. \& Goethals, C. (2007). Strategic management: a tool for public management? International Journal of Public Sector Management, 20(7), 638-654.

Flamholtz, E. \& Kurland, S. (2006). Making strategic planning work: a case study of Countrywide Financial. Handbook of Business Strategy, 7(1), 187-193.

Hahn, W. (2010). Strategic plan quality, implementation capability, and firm performance. Academy of Strategic Management Journal, 9(1), 63-81.

Hardy, J.M. (1972). Corporate planning for non-profit organizations. New York: Association Press.

Harriman, J.H.P. (2008). Creating your library's business plan. London: Facet.

Hartzell, G. (2002). Controlling your own destiny: why mission and vision statements are indispensible. School Library Journal, 48(11), 37.

Holcomb, E. L. (2001). Asking the right questions ( $2^{\text {nd }}$ ed.) Thousand Oaks, CA: Corwin Press. Johnson, I.M., Williams, C.A., Wavell, C. \& Baxter, G. (2004). Impact evaluation, professional practice, and policy making. New Library World, 105(1/2), 33-46.

Jurow, S. \& Barnard, S.B. (eds) (1993). Integrating total quality management in a library setting. NY, USA: Haworth Press.

Kent, S. (2002). The public library director in the dot (.) world. New Library World, 103(1/2), 48-54.

Kettunen, J. (2007). The strategic evaluation of academic libraries, Library Hi Tech, 25(3), 409-421.

Kirkpatrick, S. (2008). How to build a better vision statement. Academic Leadership, 6(4). Available online at http://www.academicleadership.org/emprical_research/501.shtml.

Koch, R. (2000). The financial times guide to strategy $\left(2^{\text {nd }}\right.$ ed. $)$. Great Britain: Pearson Education Ltd. Leong, J. (2008) Academic reference librarians prepare for change: an Australian case study. Library Management, 29(1-2), 77-86.

Linn, M. (2008). Library strategies: planning strategically and strategic planning. The Bottom Line:

Managing Library Finances, 21(1), 20-23.

Llewellyn, S. \& Tappin, E. (2003). Strategy in the public sector: management in the wilderness. Journal of Management Studies, 40(94), 955-982.

McClamroch, J., Byrd, J.J. \& Sowell, S.L. (2001). Strategic planning: politics, leadership and learning. The Journal of Academic Librarianship, 27(5), 372-378.

McNicol, S. (2005). The challenge of strategic planning in academic libraries. New Library World, 106(1218/1219), 496-509.

Orndoff, K. (2002). Strategic tools for RIM professionals. Information Management Journal, 36(6), 65-71.

Pacios, A.R. (2004). Strategic plans and long-range plans: is there a difference? Library Management, 25(6/7), 259-269.

Pacios, A.R. (2007). The priorities of public libraries at the onset of the third millennium. Library Management, 28(6/7), 416-427. 
Parry, J. (2008). Librarians do fly: strategies for staying aloft. Library Management, 29(1-2), 41-50. Penniman W.D. (1999). Strategic planning to avoid bottlenecks in the age of the internet. Computers in Libraries, 19(1), 50-53.

Piorun, M. (2011) Evaluation of strategic plans in academic medical libraries. Library \& Information Science Research, 33(2011), 54-62.

Presley, J.B. \& Leslie, D.W. (1999). Understanding strategy: an assessment of theory and practice. In J.C. Smart (Ed.), Higher education: handbook of theory and research, 14, (pp. 201-239). New York: Agathon Press.

Riggs, D.E. (1984). Strategic planning for library managers. Phoenix, Arizona: Oryx Press.

Roberts, S., \& Rowley, J. (2004). Managing information services. London: Facet Publishing.

Rossi, P.H., Lipsey, M.W., \& Freeman, H.E. (2004) Evaluation: a systematic approach ( $7^{\text {th }}$ ed.). Thousand oaks, CA: Sage Publications.

Rowley, D.J., Lujan, H.D. \& Dolence, M.G. (1997). Strategic change in colleges and universities: planning to survive and prosper. San Francisco: Jossey-Bass.

Schön, D.A. (1971). Beyond the stable state. London: Temple Smith.

Scottish Executive \& SLIC (2007). Building on success: a public library quality improvement matrix.

Scotland: SLIC.

Siess, J.A. (2002). Time management, planning, and prioritization for librarians. Lanham, Maryland:

Scarecrow Press.

Smith, R.J. (1994). Strategic management and planning in the public sector. Essex: Longman.

Stuart, R.D. \& Moran, B.D. (1998). Library and Information Center Management (5th ed.). Englewood, Colorado: Libraries Unlimited. 